\title{
A descentralização como modo de redefinição do poder autoritário? Algumas reflexões a partir de realidades africanas
}

Decentralization as a way of redefining authoritarian power? Some thoughts prompted by African realities

La décentralisation comme mode de redéfinition de la domination autoritaire?

Quelques réflexions à partir de situations africaines

René Otayek

Tradutor. Maria Benedita Bettencourt

\section{(2) OpenEdition}

Journals

Edição electrónica

URL: http://journals.openedition.org/rccs/793

DOI: $10.4000 /$ rccs. 793

ISSN: 2182-7435

Editora

Centro de Estudos Sociais da Universidade de Coimbra

Edição impressa

Data de publição: 1 junho 2007

Paginação: 131-150

ISSN: 0254-1106

Refêrencia eletrónica

René Otayek, «A descentralização como modo de redefinição do poder autoritário? Algumas reflexões a partir de realidades africanas », Revista Crítica de Ciências Sociais [Online], 77 | 2007, posto online no dia 01 outubro 2012, consultado o 10 dezembro 2020. URL : http://journals.openedition.org/rccs/793 ; DOI : https://doi.org/10.4000/rccs.793

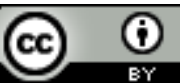




\title{
RENÉ OTAYEK
}

\section{A descentralização como modo de redefinição do poder autoritário? Algumas reflexões a partir de realidades africanas}

\begin{abstract}
A relação entre descentralização, democratização e participação política impõe-se hoje como indiscutível, tanto no discurso das entidades financeiras como no dos actores estatais e locais. De carácter essencialmente normativo, auto-profético até, este discurso é contrariado em África, onde a retórica descentralizadora parece adaptar-se muito bem às transições democráticas falhadas ou às "restaurações autoritárias". Este artigo parte da hipótese de que a descentralização é um tema estratégico para os poderes autoritários, que a usam como prova da sua conversão à ordem democrática, sem que a sua natureza autoritária seja posta em causa. A descentralização será, assim, menos o sinal de uma democratização bem encaminhada do que a medida das capacidades de adaptação de poderes autoritários às novas circunstâncias criadas por transformações internas (reivindicações democráticas, despertar da "sociedade civil") e internacionais (Consenso de Washington), de cuja conjugação resultam a desresponsabilização e a reorganização do Estado, em benefício de novos actores infra-estatais e de novos modelos de regulação libertos da sua tutela.
\end{abstract}

\section{Introdução}

A relação entre descentralização, democratização e participação política impõe-se, hoje em dia, como uma evidência indiscutível, tanto no discurso dos investidores como no dos governantes e dos agentes da sociedade civil, ${ }^{1}$ cujas implicações se encontram no cerne das reformas descentralizadoras empreendidas um pouco por todo o lado, no Norte como no Sul. Num relatório datado de 1990, o Banco Mundial enumerava, assim, doze países em vias de desenvolvimento, num conjunto de setenta e cinco, que, à época, não tinham ainda iniciado um processo de instituição de poderes locais, qualquer que fosse a sua forma política e institucional (Olowu e Wunsch, 2004). A descentralização impõe-se, pois, claramente, como uma norma universal,

\footnotetext{
${ }^{1}$ Noção vaga e polissémica, que utilizamos aqui unicamente por uma questão de comodidade linguística. Para uma abordagem crítica, cf. Otayek, 2002.
} 
estreitamente associada à universalização de uma outra norma, a democracia de mercado, único "produto" doravante disponível no mercado do "design" institucional e ideológico, desde a derrocada do modelo soviético. Arrastada na "terceira vaga" de democratização, no início dos anos noventa, a África subsariana não escapa à regra segundo a qual democratização se conjuga invariavelmente com descentralização. Raríssimos são, com efeito, os Estados que não decidiram descentralizar, segundo ritmos e modalidades diferentes, mas em nome dos mesmos objectivos de promoção da democracia local, do desenvolvimento, da eficácia administrativa, de uma melhor governação e da racionalização das opções económicas e orçamentais.

De natureza essencialmente normativa, este discurso de função explicitamente legitimadora produz efeitos muito para além das redes de agentes (investidores, elites nacionais e locais do Sul, dirigentes associativos, etc.) ligados, pelo estatuto e envolvimento no processo de reformas institucionais, ao seu carácter auto-profético e performativo. ${ }^{2}$ Com efeito, uma parte não despicienda da produção científica consagrada às descentralizações africanas (mas não apenas africanas...) peca também por normativismo, enunciando o que a descentralização deve ser e não o que ela realmente é, quando não se focaliza, de forma grosseira, no argumento da redução da pobreza, apreendida em termos técnicos que se pretendem neutros porque fundados na suposta objectividade das regras económicas. Num caso como no outro, duas constatações se impõem: por um lado, a análise do "valor acrescentado" democrático, todavia considerado consubstancial à descentralização, permanece muito lacunar, para não dizer muito frequentemente inexistente; por outro, a arena política local vê-se completamente despolitizada, reduzida a um campo de interacções entre uma multiplicidade de parceiros envolvidos numa negociação sem objectivos políticos claramente formulados e disputados, quando afinal a descentralização se traduz muitas vezes numa deslocação dos conflitos de poder do centro para a periferia, mas sem que estes percam em nada a sua acuidade e intensidade. Como salienta J. C. Ribot, "a maioria dos resultados atribuídos à descentralização são tidos como pressupostos pelos estudos publicados e não são problematizados. Saber se, onde e quando estes resultados efectivamente se concretizam é uma questão empírica que necessita de ser analisada" (Ribot, 2002: 8). Dito de outro modo, a avaliação científica das reformas descentralizadoras empreendidas em África continua, em larga medida, por fazer, nomeadamente por causa da escassez de estudos empíricos disponíveis.

\footnotetext{
${ }^{2}$ Para uma exemplificação, cf. Brunet, 1997.
} 
Esta observação crítica assume uma particular importância no que respeita às situações africanas em que a generalização da retórica descentralizadora parece adaptar-se, aparentemente sem contradição, a transições democráticas abortadas (Togo, Gabão, Camarões, Zimbabué) ou a "restaurações autoritárias” (Congo, Chade, República Democrática do Congo) cuja recorrência nos leva a questionar as distinções, que julgávamos bem estabelecidas, entre regimes "democráticos" e "autoritários", sabendo que as categorias intermediárias que encontramos na transitologia e na consolidologia mais não fazem, muitas vezes, do que aumentar a confusão. ${ }^{3}$ De uma maneira mais precisa, colocaremos a hipótese de a descentralização representar um recurso político e institucional de que os poderes pós-transicionais se apropriam e reivindicam como prova da sua conversão à ordem democrática, sem que, todavia, seja fundamentalmente posta em causa a sua natureza autoritária: em duas palavras, mudar tudo para que nada mude. Reperspectivada deste modo, a descentralização seria menos o sintoma de uma democratização bem empreendida do que o teste das capacidades de adaptação dos poderes autoritários à repartição de forças induzida pelas transformações do ambiente interno (reivindicações democráticas, "despertar da sociedade civil”) e internacional (consenso de Washington) cuja conjugação leva ao descomprometimento do Estado e à sua reorganização em benefício de novos agentes infra-estatais e de novos modos de regulação libertos da sua tutela, ou no seio dos quais este não passa de um agente entre outros.

\section{Reformas impostas do exterior}

Pouco contestadas na sua essência, mesmo se a sua implementação e as disfunções que a têm acompanhado atiçam hoje em dia as críticas, obrigando as instituições financeiras internacionais a repensar os seus modos de intervenção (Gore, 2000), ${ }_{4}^{4}$ as reformas descentralizadoras em África, e contrariamente ao que sucede no Norte, têm por característica primeira o serem impulsionadas do exterior pelos investidores internacionais. São, pois, impostas a Estados subsarianos que dispõem de uma margem de manobra drasticamente limitada, em virtude da dramática degradação da sua situação económica e financeira. Mas, mesmo neste contexto, o poder de pressão política dos investidores continua a ser modesto, restringido como está pelo respeito dos princípios de "soberania e apoliticismo das suas intervenções

\footnotetext{
3 Cf. Camau e Geisser, 2003: 31-36. Para uma crítica da transitologia, cf., entre outros, Carothers, 2002: 5-21.

${ }^{4}$ Cf. igualmente Stiglitz, 2002.
} 
e pela concorrência selvagem a que entre si se entregam, retomada, quando não iniciada, por dirigentes africanos que se posicionam para identificar e agarrar as novas oportunidades abertas pela produção de novos processos" (Darbon, 2003: 137).

\subsection{Descentralização e crise do Estado autoritário}

Como já dissemos atrás, as actuais reformas descentralizadoras em África são um fenómeno recente, intimamente ligado aos processos de transição política iniciados no começo da década de noventa. É certo que já no passado, um pouco por todo o sul do Sara, se haviam verificado diversas tentativas de reorganizar os modos de articulação entre centro e periferias, com base numa redistribuição de poderes entre o Estado e as colectividades locais - círculos, autarquias, departamentos, províncias, regiões, etc. - criadas em função das circunstâncias. Essas reformas, porém, não tiveram nunca o carácter global e sistemático de que pode gabar-se o fenómeno actual. Se é, pois, incontestável que este último deve ser visto como um fenómeno de longa duração, não é menos verdade que as reformas em curso se inscrevem num ambiente político e económico radicalmente diferente, tanto no plano interno como externo, mesmo que apresentem analogias de ordem funcional ou discursiva com as experiências passadas.

Com efeito, o carácter forçado das descentralizações actuais é consequência directa da crise do Estado pós-colonial autoritário. Económica e política, esta crise, cuja análise gerou uma vastíssima literatura, constituiu pretexto para que se pusesse radicalmente em causa o seu papel. Com o ajustamento estrutural a que foi submetido, o Estado viu escapar-lhe o controlo das decisões económicas e financeiras estratégicas, em benefício das instituições de Bretton Woods e dos países dadores bilaterais. O mito que dele fazia o principal agente de desenvolvimento caiu, pois, por terra, consumando o fracasso das ideologias do desenvolvimento sobre as quais havia construído a sua legitimidade. $\mathrm{O}$ autoritarismo erigido em modo corrente de governação perdia assim a sua principal fonte de legitimação, tanto mais que o fracasso não era apenas económico - o Estado autoritário mostrou-se incapaz de promover o desenvolvimento, atestando desse modo a incompetência das ditaduras africanas nesta matéria - mas também político - pois o Estado revelou-se igualmente incapaz de realizar a unidade nacional. O golpe de misericórdia ser-lhe-ia, finalmente, vibrado pela derrocada do bloco comunista, que acabou de desacreditar o modelo de partido-Estado em que se haviam inspirado os regimes africanos de partido único, tanto de orientação liberal (Costa do Marfim, Togo, Quénia, Camarões, etc.) como "socialista" (Benim, Angola, Congo, Moçambique, Gana, etc.) 
Trazida pela universalização da norma liberal e por teses que valorizam o lean state (Estado leve), ou ainda o Estado mínimo, processo em si mesmo revelador de uma "crise de confiança" (Vénard, 1993: 25) em relação ao Estado, a crítica do Estado autoritário alimentou poderosamente o discurso, hoje em dia dominante, sobre as supostas virtudes da descentralização e da emergência de poderes locais fomentadores, em princípio, da participação política. Como observa ainda J.-L. Vénard, "o efeito mais visível desta crise de confiança é o conjunto de reformas, visando a política económica e as instituições públicas, que são impostas como condição dos apoios financeiros ao ajustamento estrutural. Estas reformas tendem todas a reduzir o peso das administrações centrais sobre a economia nacional, tanto no que respeita ao seu poder de intervenção como no montante das suas retenções sobre a produção ou as trocas" (Vénard, 1993: 25).

Insistir, no entanto, sobre o carácter exógeno e forçado das reformas em África não significa, de forma alguma, que elas não tenham sido objecto de processos de apropriação, como veremos mais adiante, mesmo se a adesão das elites africanas à ordem descentralizadora continua, em muitos casos, mimética e formal. Com efeito, não obstante a estreita margem de manobra, o Estado africano reformado mostrou, e continua a mostrar, capacidades constantemente renovadas de contornar e instrumentalizar as regras do jogo decretadas pelos investidores, esvaziando assim as reformas da sua substância e reduzindo-as a um simples problema de gestão e de técnicas administrativas desligadas das questões políticas, todavia inerentes a qualquer reforma. Neste contexto, a hipótese de que a crítica neoliberal assinaria a "destruição" do Estado, em nome de o desonerar, deve ser consideravelmente matizada (mesmo se a crítica do autoritarismo degenerou por vezes num processo de deslegitimação do Estado), uma vez que a desoneração em causa se inscreve menos num processo de desestatização absoluta, mesmo que fosse "imposta" (Coussy, 1994: 232), do que de "reconfiguração" do Estado num ambiente propício à "multiplicação dos constrangimentos e também das oportunidades internacionais" (Hibou, 1997: 7). A reforma será pois, simultaneamente, um constrangimento e um recurso que os Estados do Sul mobilizam tanto melhor quanto ela lhes é entregue, "chaves na mão", pelos Estados do Norte que fizeram do apoio à descentralização um eixo central das suas políticas de cooperação em África, e isto por duas razões fundamentais: por um lado, porque se acredita, numa visão idealizada, que a descentralização favorece a participação, ao organizar uma "profunda transformação dos mecanismos do poder” (Banégas e Quantin, s.d.: 4-9); por outro, porque, sendo o referencial comum destas reformas o modelo europeu, a generalização das 
reformas descentralizadoras legitima a visão ocidental do político e reforça a sua universalização.

\subsection{Descentralização e tipo de regime político: uma relação equívoca}

A hipótese de uma articulação positiva entre descentralização, democratização e participação é tanto mais problemática quanto a observação de longo prazo demonstra que não existe uma correlação unívoca entre descentralização e tipo de regime político, pelo menos em África. As diferentes fórmulas ensaiadas, aqui e ali, logo a seguir às independências, ou até mesmo sob o regime colonial cujo modo de administração, directa ou indirecta, podia ser qualificado como "despotismo descentralizado" (Mamdani, 1996), para sublinhar o carácter intrinsecamente autoritário, quando não violento, da "situação colonial" (G. Balandier), foram assim obra tanto de regimes (civis ou militares) autoritários como de regimes que ostentavam um certo grau de liberalismo político e de respeito pelo pluralismo. No primeiro caso, a Costa do Marfim aparece como uma espécie de exemplo paradigmático da descentralização em contexto autoritário, ao passo que, no segundo, é o Senegal que se impõe como "modelo" de descentralização em contexto liberalizado, um "modelo" único no espaço francófono, por certo, cuja historicidade, irredutível, remete para a experiência municipal das "quatro autarquias" que marca a história e a cultura políticas deste país desde a segunda metade do século XIX. ${ }^{6}$ Descentralização e democracia não vão, pois, forçosamente a par, da mesma forma que o autoritarismo pode perfeitamente acomodar-se à existência de poderes locais... na condição, porém, de que estes não se arvorem em contra-poderes e que a sua autonomia seja rigorosamente controlada.

A recorrência e a diversidade das políticas de descentralização desenvolvidas em África desde o início dos anos sessenta, e mesmo antes, validam esta observação. Com efeito, as veleidades descentralizadoras dos Estados subsarianos esbarraram constantemente na contradição - insolúvel, tendo em conta o seu carácter autoritário e neopatrimonial ${ }^{7}$ - entre os dois princípios de autoridade e de liberdade, cuja regulação institucional funda, no Norte, a articulação entre poder central e colectividades locais (Pontier, 1978: 7). Uma vez dobrado o cabo das independências (início dos anos sessenta), depressa se fez tábua rasa, um pouco por todo o lado, da expe-

\footnotetext{
${ }^{5}$ Sobre esta questão, cf. B. Badie, 1992.

${ }^{6}$ Dakar, Saint-Louis, Gorée e Rufisque, cujos habitantes gozam do estatuto de cidadania desde 1833 e elegem os seus deputados desde 1848.

${ }^{7}$ Sobre a noção de neopatrimonialismo cf. J.-F. Médard, 1990.
} 
riência colonial nesta matéria, ${ }^{8}$ uma experiência por vezes considerada a idade de ouro da descentralização em África, quando, na verdade, foi concebida, não para promover a democracia e a participação política, mas para permitir a administração das colónias a menor custo. Desde então, as experiências foram-se sucedendo ao mesmo tempo que se acumulavam as reformas, ao sabor das transformações do ambiente interno e internacional, e isto nomeadamente a partir dos anos setenta e da progressiva afirmação do Banco Mundial como provedor de mecanismos de sobrevivência financeira para os Estados subsarianos em situação economicamente calamitosa, bem como da difusão das teses neoliberais e do consenso internacional sobre... o "Consenso de Washington". A conjugação destes diferentes factores consagra a "mundialização do mercado das reformas administrativas" e favorece a "formatação dos 'sets' de reforma segundo um modelo único muito influenciado pelos interesses, debates, arenas e fóruns do Norte" (Darbon, 2003: 136).

Os governos africanos reagem a estes inputs tentando adaptar-se, mas sem pôr em causa a natureza do Estado e das suas relações com a sociedade, como atesta a litania das reformas empreendidas: logo após as independências, a hora é de exaltação da nação, erigida em verdadeira religião civil, e da omnipotência do partido-Estado que pretende ser a sua encarnação e o instrumento da sua criação. O ideal descentralizador continua a ser afirmado, mas está subordinado a um princípio superior, o da unidade nacional. A contradição é insolúvel.

Os anos de 1970-1980 são os do ajustamento estrutural e das políticas de desoneração do Estado. Flagelados pela crise da dívida, os Estados mutualistas (Costa do Marfim, Nigéria, Congo, Zaire, Camarões, Quénia), vêem desmoronar-se as suas capacidades redistributivas, graças às quais se efectuava a regulação neopatrimonial. Coagidos a aceitar as reformas sob pressão dos investidores, aproveitam a ocasião para se reorganizar e reconfigurar. É a hora da "sociedade civil" e das grassroots organizations, um advento algo extemporâneo, na medida em que, por falta de meios, o Estado africano havia já, desde há muito, consentido em transferir de facto algumas das suas competências, nomeadamente em matéria de educação, saúde e habitação. A diferença, importante, reside no facto de a desoneração ser agora sistematizada, formalizada e submetida aos condicionalismos do Banco Mundial, que, numa atitude fortemente inspirada pelas teorias da rational choice,

\footnotetext{
${ }^{8}$ Uma experiência, precisemos, que só adquire verdadeiramente forma e consistência no início dos anos cinquenta, com o princípio de liberalização do regime colonial que preludia as independências. Assim, em 1955, existem já 44 autarquias ditas de "pleno exercício" na AOF (África Ocidental Francesa).
} 
compromete os Estados beneficiários ou requerentes da sua ajuda a utilizar "economias e instituições paralelas ou informais como instrumentos alternativos de fornecimento de serviços" em nome da "concorrência, no seio do sector público, na produção de serviços e bens" (Olowu e Wunsch, 2004: 35). As instituições locais criadas para satisfazer os critérios do Estado "modesto" são quer ineficazes, quer simples extensões do poder central, entendendo-se que a descentralização deve, segundo o Banco Mundial, ser feita a custos constantes, ou seja, "sem aumentar o número dos funcionários dos governos locais" (ibid.: 35). Fonte de constrangimento para os Estados africanos, que vêem serem-lhes impostas reformas cuja inspiração ideológica, agenda, conteúdo e modalidades de implementação lhes escapam por completo, este mecanismo não é, no entanto, totalmente desprovido de vantagens para eles: por um lado, porque legitima a transferência (na realidade, desde há muito iniciada) para as colectividades locais de competências que a sua situação financeira já não lhes permitia, em todo o caso, assumir; por outro, porque lhes permite aproveitar a fragilidade dessas novas colectividades locais para assegurar o seu controlo e organizar a sua dependência em relação ao poder central, através da nomeação para lugares-chave de representantes seus. Foi, nomeadamente, o que se passou na Costa do Marfim, nos Camarões ou no Gana com as "district assemblies". Um pouco por todo o lado, verifica-se, pois, um processo não de descentralização, mas de desconcentração, que só marginalmente abala a preeminência do centro, não induz nenhuma verdadeira redistribuição de poder e autoriza o Estado africano a valer-se da sua capacidade de reforma segundo os preceitos do Banco Mundial e dos peritos internacionais constituídos em "comunidade epistémica”, alargada a certos responsáveis africanos (chefes de Estado, funcionários internacionais, peritos nacionais, etc.) que com eles mantêm "transacções de conluio".

As transições políticas do início dos anos noventa conferem um novo impulso à descentralização. Embora o argumento do desenvolvimento e da luta contra a pobreza continue a ter um papel central, a tónica é doravante posta energicamente no "valor acrescentado democrático" de que a descentralização seria portadora. O discurso descentralizador quer-se doravante "político", articulando estreitamente democratização e descentralização, e baseando-se no pressuposto de que a segunda irá consolidar a primeira por favorecer o aparecimento de novos intervenientes, a mobilização da "sociedade civil", a construção de um campo político local e a renovação das práticas participativas; mas a verdade é que as descentralizações empreendidas permanecem tributárias de uma visão essencialmente administrativa e tecnicista da reforma, "construída em torno de uma recusa declarada da 
política em redor da qual gravitam os interesses dos responsáveis políticos e administrativos locais, dos peritos nacionais ou estrangeiros e dos investidores". É o triunfo da anti-politics machine, tanto mais previsível quanto a reforma esbarra numa equação insolúvel: como empreender a transformação radical do modo de regulação estatal em que se traduzem a democratização e a descentralização, quando o instrumento escolhido para o fazer é declarado "apolítico" e "neutro", sendo reduzido a uma "minudência técnica"? "Neste contexto incerto, os poderes centrais não têm grande dificuldade em recuperar uma parte da margem de manobra consentida aos investidores, esvaziando a reforma do essencial do seu conteúdo, ao imporem, em nome da fragilidade estrutural das colectividades locais e da inexperiência das suas administrações e dos eleitos locais, medidas de desconcentração que lhes permitem empossar as arenas locais e controlar a sua dinâmica.

Neste jogo, a descentralização pode revelar-se geradora de inesperadas vantagens, prontas a serem captadas pelos Estados para fins estratégicos que, tendo embora pouco a ver com os objectivos declarados (desenvolvimento local, democracia participativa, imputabilidade, etc.) atribuídos à reforma, não deixam de ser de uma grande funcionalidade. É o que acontece, por exemplo, no Mali e no Níger, onde a descentralização tem por principal função a resolução do conflito interno que, durante longos anos, opôs o poder central às populações tuaregues do Norte, que ameaçavam tornar-se independentes; e é igualmente o caso do Uganda, onde a restauração da unidade nacional, minada por anos de guerra civil, passou pela instituição de local governments. Estes exemplos mostram de passagem que, contrariamente a uma ideia largamente difundida, a descentralização não precipita forçosamente a desconstrução "pela base" dos Estados africanos, cristalizando as forças centrífugas (etnicidades ${ }^{10}$, autoctonias ${ }^{11}$, tropismos regionais) que assim se veriam reforçadas e legitimadas; ela pode ser, pelo contrário, um instrumento de reconstrução do Estado no quadro de um equilíbrio sempre precário e flutuante entre poder local e periferias, como demonstra o caso sul-africano, em que a instituição de poderes locais dotados de amplas competências esteve no cerne do processo de refundação pós-apartheid. ${ }^{12}$ O problema é que, em muitos destes países (Mali, Níger), nos encontramos

\footnotetext{
${ }_{9}$ Darbon, 2003: 136-137. Sobre a máquina anti-política, cf. igualmente B. Jobert, 2002. Para um estudo de caso, cf. Ferguson, 1990.

${ }_{10}$ A problemática da etnicidade deu azo a uma vasta bibliografia de que seria fútil destacar determinadas referências em detrimento de outras. Citemos simplesmente, para registo, o estudo já clássico de P. Poutignat e J.-S.Streiff-Fenart (1995); e, sobre África, Coulon, 1997.

${ }_{11}$ Para uma discussão da autoctonia como modo de mobilização política, cf. Bayart et al., 2001.

${ }^{12}$ Cf., sobre este tema, a excelente tese de ciência política de Y. Crouzel (2004).
} 
mais perante um esquema de autonomia regional, uma espécie de federalismo étnico - de que a Etiópia oferece o modelo mais acabado e totalmente assumido, uma vez que o direito de secessão das províncias é aí reconhecido pela Constituição (Abbink, 1995) - que não diz o seu nome, do que de uma descentralização no sentido clássico do termo. E isto porque, neste caso, o objectivo visado é menos um empowerment da periferia do que a redefinição do seu modo de articulação com o Centro, através de medidas de desconcentração administrativa. Igualmente desvirtuada é a descentralização que, como sucede no Chade, constitui pretexto para uma retractação institucional do Estado em relação ao centro e às regiões "úteis" fornecedoras de produtos rentáveis (algodão e, desde há alguns anos, petróleo), em detrimento das outras, totalmente negligenciadas pelo regime autoritário de Idriss Déby, que ilustra até à caricatura a tese da reconfiguração do Estado; ou quando, na Somália e na República Democrática do Congo (ex-Zaire), dois collapsed states, desapareceu, ou quase, toda e qualquer forma de regulação estatal, tornando absurda a própria ideia de descentralização e engendrando, por força das circunstâncias, modos de auto-organização infra-estatais, não por vontade de descentralizar, mas porque a sociedade se vê obrigada a inventar "maneiras de fazer" sem o Estado.

\section{Dinâmicas de apropriação: "não-dito" e ambiguidade na descentralização}

Nada seria, por conseguinte, mais errado do que acreditar que os Estados subsarianos sofrem passivamente os efeitos de reformas impulsionadas do exterior. Neste ponto, não podemos deixar de nos surpreender com a extraordinária capacidade de resistência à mudança de que estes Estados, que, no entanto, acusam, em geral, um significativo défice de legitimidade e de institucionalização, deram provas frente ao ciclo ininterrupto de reformas a que se têm visto sujeitos desde o início dos anos setenta. Só, talvez, os países árabes se poderão gabar de um melhor "desempenho" na matéria, em parte, sem dúvida, porque a sua capacidade de controlo social é superior à dos Estados africanos, devido, nomeadamente, à hipertrofia dos seus aparelhos securitários e à inexistência das exit options que, em África, permitem a fuga ao domínio do Estado. A descentralização apresenta-se como um ponto de observação particularmente interessante deste fenómeno.

\subsection{A descentralização como recurso: efeitos manifestos e efeitos latentes}

A hipótese da despolitização da arena local, que seria como que por magia impermeável aos conflitos de poder, não resiste muito tempo à prova dos factos, não obstante o que persistem em dizer peritos internacionais, investidores, ou responsáveis de ONGs, agarrados a uma visão mitificada e nor- 
mativa do local, que, à imagem da díade Estado-sociedade civil, encarnaria a democracia e a virtude frente ao centro, assimilado à corrupção e à coerção. ${ }^{13}$ Podemos pensar, pelo contrário, que a descentralização não só tende a deslocalizar as lutas de poder (o que constitui, sem dúvida, um dos objectivos que dela se esperam em vista a uma regulação institucional "descentrada" destas lutas), sem forçosamente atenuar a sua intensidade, como valoriza também a arena política local, conferindo-lhe uma carga política inédita que exacerba a competição pelo seu controlo. ${ }^{14}$

Se dúvidas houvesse, bastaria observar a energia com que os pretendentes ao poder autárquico disputam os troféus electivos na altura das eleições locais, organizadas em África desde o início dos anos noventa. ${ }^{15}$ Neste enquadramento, o partido no poder goza de uma posição privilegiada - todos os recursos políticos, administrativos, financeiros e mediáticos do aparelho estatal - que lhe permite, muitas vezes, controlar o jogo eleitoral e assegurar o seu domínio sobre a arena local, aniquilando totalmente os seus adversários, ou não lhes concedendo mais do que alguns troféus destinados a legitimar a sua soberania junto dos investidores e eventuais observadores internacionais. O Burkina-Faso, para citar só este exemplo, está mais do que acostumado a este cenário, em que o todo-poderoso partido presidencial, CDP (Congresso para a Democracia e o Progresso) arrebanha habitualmente a fatia de leão nas eleições municipais, deixando apenas algumas migalhas para a oposição. Neste país, todavia apresentado como um modelo de estabilidade política, de transição democrática bem sucedida e descentralização concretizada, a hegemonia do CDP - apoiada numa Constituição feita à medida para o actual chefe de Estado, cujo número de mandatos éilimitado, e no controlo total do aparelho político e administrativo central e local é de tal ordem que qualquer ideia de alternância, possível em teoria, se torna inviável na prática. Neste contexto, o poder local reduz-se a uma simples extensão do poder central, que remata o seu empreendimento hegemónico com a conquista da arena local, das suas estruturas administrativas e instituições representativas.

Os regimes autoritários anteriores à vaga transicional dos anos noventa já tinham, aliás, avaliado a funcionalidade do local nas suas estratégias de legitimação, e alguns deles haviam-se tornado mestres na arte de o instrumentalizar. Foi o que aconteceu no Quénia sob o reinado do presidentefundador Jomo Kenyatta, que utilizou a administração provincial para

13 Sobre a díade Estado-sociedade civil como figuras inversas, cf. Newbury, 1994.

${ }_{14}$ Para um estudo de caso, cf. Bierschenk e Sardan, 1998.

15 Cf., a título de exemplo, Loada e Otayek, 1995. 
cimentar o controlo do partido único no âmbito etno-regional. O seu sucessor, Daniel Arap Moi, prosseguiu a sua obra, apoiando-se na administração distrital (Bourmaud, 1988). J. Rawlings, do Gana, fez o mesmo com as district assemblies, ao passo que, na Costa do Marfim, a descentralização foi, em grande parte, concebida para revitalizar um partido único (o Partido Democrático da Costa do Marfim-Reunião Democrática Africana, PDCI-RDA), confrontado com o envelhecimento dos seus quadros e o desgaste das suas capacidades de mobilização. ${ }^{16}$ Nesta perspectiva, o argumento da regeneração do partido e das suas estruturas pode também ser pretexto para a marginalização de certas "figuras" caídas em desgraça, descredibilizadas junto da população ou apontadas para a vingança desta em nome da luta contra a corrupção, ou até mesmo para a resolução de lutas entre facções no seio do partido único ou dominante, mediante o acesso ao poder local de novos segmentos da elite dirigente, cuja lealdade para com o centro será tanto mais forte quanto lhe devem a sua carreira política. Em contexto autoritário, como em contexto "democratizado", a descentralização surge assim como uma ferramenta particularmente funcional em matéria de circulação, cooptação e reciclagem das elites no poder, cuja instrumentalização permite ao centro assegurar a sua hegemonia, actuando como árbitro entre os múltiplos pretendentes aos troféus electivos locais e neutralizando as tensões internas que o fragilizam pela imposição, em nome da democracia, de um turn over às facções que se organizam no seu seio. Foi essa, por exemplo, a estratégia seguida no Burkina-Faso pelo CDP, aquando das eleições municipais de 2000, para a escolha dos seus candidatos, cuja selecção passou pela organização de "primárias" localmente arbitradas pelos militantes do partido, devidamente enquadrados e "aconselhados" por quadros submetidos à direcção nacional e tendo interiorizado plenamente o princípio do centralismo democrático que continua a reger o partido, não obstante o abandono oficial da referência marxista em 1989. Nestas circunstâncias, a descentralização, longe de favorecer a emergência de um poder local autónomo (ou, a fortiori, de um verdadeiro pluralismo político), legitimo e imputável, tende, pelo contrário, a retirar aos eleitos locais o seu poder de decisão em benefício do partido, de que depende a sua eleição, e dos serviços desconcentrados do Estado, cujo controlo lhe permite impor a sua agenda aos deputados eleitos. ${ }^{17}$

\footnotetext{
${ }_{16}$ Nesta perspectiva, será sempre proveitosa a leitura de dois estudos pioneiros sobre as eleições "sem escolha": Hermet et al., 1978, e, sobre África, CEAN-CERI, 1978.

${ }_{17}$ Para o estudo de um caso particularmente elucidativo, cf. Mamadou, 2003.
} 
Perante o que acabamos de expor, a hipótese da vacuidade das reformas em África, ou do seu carácter cosmético e simbólico, deve ser refutada, na medida em que esquece tanto o jogo dos agentes nelas envolvidos como os seus efeitos - reais, ainda que frequentemente pouco relacionados com o que delas se esperava. Longe, pois, de se reduzir a uma imposição sofrida, a descentralização surge como "uma opção favorável a uma consolidação do poder" (Darbon, 2003: 141) e deve ser tomada tanto mais a sério quanto é investida pelo imbróglio de interesses políticos, nacionais e locais, e participa energicamente, não só da construção de um campo político local (Le Bris, 1966), mas também, e talvez sobretudo, da cristalização de paradoxais dinâmicas territoriais. Não é, com efeito, ilegítimo perguntar se um dos efeitos "perversos" da descentralização não será favorecer um processo de territorialização tornado possível pela capacidade do partido dominante, identificado com o centro político, para captar as periferias, graças às virtudes do sufrágio universal. Nesta hipótese, a descentralização, no que significa de extensão do poder central às periferias, seria um instrumento de homogeneização territorial - um objectivo que os regimes de partido único se teriam mostrado incapazes de atingir - graças ao controlo do local, processo que não deixaria de recordar, uma vez mais, as lógicas em acção sob o Estado colonial, onde o controlo territorial passava pelo dos centros urbanos, sede e encarnação do poder europeu. O outro efeito paradoxal, complementar do anterior, consistiria num processo de recentralização do poder, favorecido pela fragilidade estrutural das colectividades locais, a dependência das elites locais em relação às do centro, e a capacidade deste último de aproveitar as oportunidades oferecidas pela descentralização para inventar novas modalidades de captação das suas periferias. A maior parte das observações feitas em países tão diferentes como o Senegal, os Camarões, o Burkina, o Gana ou a Costa do Marfim parece validar esta hipótese. ${ }^{18}$ Anteriores e posteriores aos anos noventa, essas observações confirmam o "princípio", já evocado, da inexistência de correlação entre tipo de regime político e descentralização.

\footnotetext{
18 J. C. Ribot (2002: 19) observa assim que "em 1994, mais de 300 dos 317 conselhos rurais eram dominados pelo Partido Socialista no poder” enquanto R. Crook e Sverrison (2001: 25) indicam que, na Costa do Marfim, "a política local era inteiramente controlada pelo partido (o PDCI-RDA), devido ao sistema único de lista fechada" acrescentando que "entre os presidentes dos conselhos rurais, 74 dos 125 que presidiam a conselhos rurais for a da capital residiam na capital, 29 por cento eram deputados à Assembleia Nacional e 9 por cento eram ministros ou detinham lugares elevados no governo".
} 


\subsection{A participação em questão}

A valorização da participação política está no cerne do discurso descentralizador, que vê nela o vector apropriado de mobilização para o desenvolvimento, de emergência de novos agentes e de construção de uma democracia de proximidade. Não desprovido de acentos tocquevillianos, e remetendo para uma tradição sociológica que vai de Stuart Mill a Robert Dahl, passando por Max Weber, este discurso enuncia a retórica da democracia participativa, que, pela sua recorrência e monopólio adquirido no seio das "comunidades epistémicas" de "promotores do desenvolvimento" (instituições internacionais, peritos, ONGs, etc.) se impõe doravante como uma "neo-tradição" (Chauveau, 1994), em detrimento de uma outra "neo-tradição", que era a do desenvolvimento "a partir do topo", marcante nos anos setenta. Assentando num certo número de postulados articulados em torno da ideia de "boa governação" ${ }^{19}$, inventada pelos peritos internacionais, no final dos anos oitenta, para "acompanhar" as reformas políticas e económicas impostas aos países da África subsariana, a retórica participativa encontrou um terreno de experimentação privilegiado na descentralização, enquanto quadro político favorável à institucionalização dos processos de negociação e compromisso que implicam a mobilização e a acção colectiva. Mas esta visão apolítica do desenvolvimento local coloca mais questões do que as que resolve. Aqui, ocupar-nos-emos de apenas duas.

A primeira diz respeito a um dos argumentos centrais da retórica participativa, a emergência e o empowerment de novos agentes libertos das lógicas sociais (clientelismo, traficâncias, vassalagens "primárias", lealdades ideológicas) que se desviam da participação ou, na melhor das hipóteses, lhe subvertem o sentido. Ora, este argumento é contestável a diversos títulos. Por um lado, subestima a capacidade de adaptação das elites locais, "tradicionais" e modernas, à nova estrutura de oportunidades proporcionada pela implementação das políticas públicas locais, bem como a sua aptidão para lhes captarem os benefícios, ao imporem-se como intermediários obrigatórios entre a população e a administração local. É o que se verifica, por exemplo, nas estruturas dominadas por "notáveis", e nomeadamente, nos territórios sob autoridade de um chefe local (chefferies), que as reformas descentralizadoras relegitimaram em nome da eficácia política e administrativa. Ora, todos os estudos sobre a problemática da gestão dos recursos naturais, que são de uma importância crucial em África e, nessa medida, objecto de numerosas políticas sectoriais, concluem pela capacidade

\footnotetext{
19 A discussão do conceito de governação gerou acesos debates, ao dossier dos quais acrescentamos uma das últimas obras sobre a questão: Hermet et al., 2005.
} 
deste poder dos notáveis de se apropriar dos recursos locais, posicionando-se no centro dos processos de negociação e decisão. Um exemplo entre outros: no Burkina, a criação de cooperativas de criadores de gado e de comerciantes no Norte do país contribuiu, paradoxalmente, para reforçar o poder dos chefes, que se viram "em posição de centralizar os fundos necessários e presidir à sua redistribuição" (Pollard, 1993). Observações relativas às políticas de gestão do ambiente no Senegal vão no mesmo sentido, interrogando-se sobre a equidade da distribuição "dos custos e das vantagens associados aos projectos ou às reformas institucionais" (Utting e Jaubert, 1998). O mesmo acontece com líderes de ONGs e outros "mediadores locais de desenvolvimento" que, pela sua capacidade de se apropriarem das normas internacionais e se conectarem às fontes de financiamento exterior, se impõem como portadores privilegiados dos projectos locais de desenvolvimento e "a interface entre os destinatários do projecto e as instituições de desenvolvimento" (Bierschenk et al., 2000: 7). Colocados no papel de árbitro, estes "mediadores" estão em posição de controlar os circuitos de participação por diferentes meios (aliança com os eleitos locais, monopolização do poder de proposta, controlo dos processos administrativos, etc.), isto quando não se encontram, eles mesmos, subordinados às lógicas familiares e clânicas.

Por outro lado, este argumento é criticável na medida em que postula implicitamente a homogeneidade da sociedade, ignorando por isso as suas clivagens, os seus conflitos e as suas relações de força. Esta imagem de África inscreve-se na linha do que um dos melhores historiadores do continente chama o "discurso do costume" (Lonsdale, 1999: 143), que declina a sociedade africana ideal, fixada na sua imutabilidade cultural e no seu unanimismo político, um discurso totalmente apropriado pela comunidade de "promotores do desenvolvimento" e sistematizado sob o rótulo de desenvolvimento "comunitário" ou "participativo". ${ }^{20}$ Este "paradigma" culturalista da autenticidade é de tal forma obsidiante que as reformas pecam frequentemente por "esquecimento" ou subestimação dos aspectos políticos da participação, nomeadamente a organização e a mobilização dos grupos sociais subordinados, assim como a permeabilidade do local às dinâmicas políticas globais, nacionais e internacionais. Nestas condições, a participação comunitária encontra-se frequentemente reduzida a um simples processo de consulta técnica em que os peritos e os serviços administrativos se substituem, em nome da sua competência, não só às populações interessa-

${ }^{20}$ Para uma análise mais aprofundada desta questão, impossível de fazer no quadro deste artigo, pode consultar-se Otayek, 2000, nomeadamente págs. 61-67. 
das, mas também às instâncias representativas - os eleitos - remetidos para a categoria de modestos advisory groups que não deixam de recordar as práticas administrativas coloniais (Ribot, 2002: 16). Para além de esvaziar de sentido a democracia local, este processo não pode igualmente deixar de induzir uma crise da representação local, seja porque a população, desiludida, retira a confiança aos eleitos, acentuando com isso o défice de legitimidade destes, seja porque o comportamento predador destes eleitos ${ }^{21}$ impõe a exit option como única alternativa possível. Em todos os casos, o resultado é um desinteresse pela política que favorece o controlo da participação pelo poder central e os seus representantes locais - o que constitui uma, se não $a$ característica distintiva dos regimes autoritários ${ }^{22}-$ e a asfixia da mobilização visada pela retórica participativa.

Neste ponto, não podemos deixar de nos interrogar sobre um outro argumento igualmente consubstancial à retórica participativa: a sociedade civil. É a segunda e última questão que abordaremos resumidamente aqui, uma vez que já a analisámos desenvolvidamente noutras ocasiões. ${ }^{23}$ Como é sabido, a ideia de sociedade civil deu e continua a dar azo a debates científicos cuja intensidade se pode considerar equivalente à recorrência das instrumentalizações ideológicas de que ela é objecto. Mas reconhecer os limites explicativos desta ideia não nos dispensa de a levar a sério, na medida em que ela faz doravante parte do léxico dos agentes sociais, tanto do Norte como do Sul. ${ }^{24}$

Vejamos, nomeadamente, o caso da gestão participativa, de que se diz, na linha das observações tocquevillianas acerca do dinamismo associativo americano, representar uma aspiração natural das populações, cuja mobilização no seio das instituições constitutivas da sociedade civil (ONGs, associações, movimentos religiosos, etc.) abriria caminho à democracia e ao desenvolvimento. Nesta perspectiva, a descentralização surgiria em res-

\footnotetext{
${ }^{21}$ Na Nigéria, sublinham Olowu e Wunsch (2004: 66), “os funcionários locais eleitos parecem candidatar-se, em primeira linha, para desenvolver oportunidades de negócio e quanto mais recursos e autoridade parecem existir localmente maior parece tornar-se a porção que se escoa”.

${ }^{22} \mathrm{Na}$ esteira de J. Linz, M. Camau e V. Geisser (2003: 39) identificam o regime autoritário através de duas características: "a limitação do pluralismo e a despolitização dos cidadãos".

${ }^{23}$ Cf. nomeadamente, Otayek, 2000: 121-129; 2002.

${ }^{24}$ Relativamente a este ponto, não podemos deixar de nos surpreender com as críticas de P. Chabal e J.-P. Daloz, que nos acusam de obediência a uma visão ideológica e normativa da sociedade civil, confundindo assim os "bons sentimentos militantes" que nos atribuem com a preocupação de compreender o lugar que o discurso sobre a sociedade civil ocupa nas estratégias dos agentes e na acção colectiva (Chabal e Daloz, 2002). Estas críticas ainda se tornam mais incompreensíveis se atendermos ao facto de que o nosso contributo na obra acima citada foi justamente consagrado, em parte, à desconstrução das concepções ideológicas e normativas da sociedade civil. Cf. Otayek, 2004.
} 
posta a um apelo mais ou menos articulado da "base" e significaria "uma reapropriação do poder, do qual implicitamente se supõe que o povo terá sido desapossado pelas práticas anteriores de favorecimento dos "notáveis'" (Balme, 1989: 85). Mas este argumento é discutível por, pelo menos, três razões. Por um lado, a observação mostra, pelo contrário, que a descentralização é, na maioria das vezes, impulsionada a partir do topo, e é no topo que ela é pensada em termos de política pública e traduzida em objectivos. É esta, em todo o caso, uma das conclusões a que chegam R. C. Crook e J. Manor (1998) no final de uma análise comparativa de quatro experiências descentralizadoras em África e na Ásia. Uma das raras excepções a este esquema geral, excluindo o caso sul-africano, evocado mais atrás, é a Nigéria, onde a criação de local governments por "cissiparidade" se inscreve claramente em estratégias totalmente assumidas pelas elites locais e se explica à luz das lógicas de redistribuição dos rendimentos do petróleo, inerente ao sistema federal em vigor. ${ }^{25}$ Por outro lado, mesmo se não emana das populações um claro apelo ao Estado, e mesmo se estas se mobilizam voluntariamente em torno de projectos de interesse colectivo, será, sem dúvida, menos por um espírito revanchista contra o Estado do que porque, confrontadas com a demissão deste, não têm outra alternativa que não seja auto-organizarem-se para compensar essa desoneração. Enfim, este argumento é contestável na medida em que decorre de uma visão mitificada da sociedade civil, da qual postula também a homogeneidade, a capacidade de ser a depositária do bem público e a faculdade de dispensar a acção organizadora do Estado. Podemos, pelo contrário, pôr a hipótese de que o voluntarismo, ou até mesmo a espontaneidade inerentes ao desenvolvimento participativo, exprimem talvez mais "uma desorientação do que uma visão social renovada" (Dubresson et al., 1994: 74), sobretudo num contexto em que à debilidade estrutural da fiscalidade local acresce a recusa ou a incapacidade do poder central de transferir os recursos orçamentais que, em princípio, acompanham a transferência de competências para as colectividades locais, mantendo-as assim na sua dependência.

\section{Conclusão}

Longe de ser esse mecanismo neutro portador de uma partilha do poder, a descentralização surge antes como o último estratagema dos regimes pós-transicionais africanos para se reformularem sem porem radicalmente em causa a sua natureza, em relação à qual os mentores internacionais das

${ }^{25}$ Sobre as dinâmicas de cissiparidade do federalismo nigeriano, cf. nomeadamente os trabalhos de D. Bach. 
reformas só marginalmente se interrogam. Nesta óptica, a reconfiguração dos modos de articulação entre periferias e centro, assim como a redução do papel do Estado nos planos político e económico, resultam muitas vezes em estratégias de sobrevivência, em que a simples racionalidade política manda que se façam concessões à periferia para não conceder nada de fundamental ao centro. Mas, mesmo nesta hipótese, a automutilação consentida pelo poder central é largamente compensada pela sua capacidade de retomar com uma mão o que dá com a outra, seja esvaziando a descentralização do seu potencial "democratizante", ao aplicá-la apenas parcialmente (ou seja, em domínios que não ameaçam a sua hegemonia), seja reorganizando, por diversos meios, a dependência das periferias em relação a si, ou ainda fazendo da prática da descentralização uma questão técnica e burocrática, no quadro da qual os agentes sociais, reduzidos à categoria de executantes, são simples súbditos. Talvez se encontre aí uma pista que explique a espantosa recorrência das transições sem alternância em África.

Tradução de

Maria Benedita Bettencourt

\section{Referências bibliográficas}

Abbink, J. (1995), “Ethnicité et 'démocratisation': le dilemme éthiopien”, Politique Africaine, 7, 135-141.

Balme, R. (1989), “L'association dans la promotion du pouvoir municipal”, in A. Mabileau; C. Sorbets (orgs.), Gouverner les villes moyennes. Paris: Pedone.

Banégas, R.; Quantin, P. (s.d.), Orientations et limites de l'aide française au développement démocratique: Bénin, Congo et République centrafricaine. (policop.).

Bayart, J.-F. et al. (2001), “Autochtonie, démocratie e citoyenneté en Afrique”, Critique Internationale, 10, 177-194.

Bierschenk, T. et al. (org.) (2000), Courtiers en développement. Les villages africains en quête de projets. Mayence-Paris: APAD-Karthala.

Bierschenk, T.; Sardan, J.-P. Olivier de (orgs.) (1998), Les pouvoirs au village. Le Bénin rural entre démocratisation et décentralisation. Paris: Karthala.

Bourmaud, D. (1988), Histoire politique du Kenya: Etat et pouvoir local. Paris/Nairobi: Karthala-CREDU.

Brunet, Françoise (1997), La décentralisation en Afrique subsabarienne. Paris: Secrétariat d'Etat à la décentralisation.

Camau, M.; Geisser, V. (2003), Le syndrome autoritaire. Politique en Tunisie de Bourguiba à Ben Ali. Paris: Presses de Sciences Po.

Carothers, T. (2002), “The End of the Transition Paradigm”, Journal of Democracy, 1, $5-21$. 
CEAN-CERI (1978), Aux urnes l'Afrique! Elections et pouvoirs en Afrique noire. Paris: IEP de Bordeaux-CEAN, Pedone.

Chabal, P.; Daloz, J.-P. (2002), "How Does Africa Works Work? Retour sur une lecture hétérodoxe du politique en Afrique noire", in Maria Cristina Ercolessi; Alessandro Triulzi (orgs.), State, Power, and New Political Actors in Postcolonial Africa. Milano: Feltrinelli, 113-129.

Chauveau, J.-P. (1994), "Participation paysanne et populisme bureaucratique", in J.-P. Jacob; Lavigne-Delville (orgs.), Les associations paysannes en Afrique. Organisation et dynamiques. Paris: Karthala, 25-60.

Coulon, C. (1997), "Les dynamiques de l'ethnicité en Afrique noire”, in P. Birnbaum (org.), Sociologie des nationalismes. Paris: PUF, 37-53.

Coussy, J. (1994), “Les ruses de l'Etat minimum”, in J.-F. Bayart (org.), La réinvention du capitalisme. Paris: Karthala, 227-248.

Crook, R. C.; Manor, J. (1998), Democracy and Decentralization in South Asia and West Africa. Participation, Accountability and Performance. Cambridge: CUP.

Crook, Richard C.; Sverrison, Alan S. (2001), Decentralisation and poverty-alleviation in developing countries: a comparative analysis, or is West Bengal unique?, IDS (Institute for Development Studies) Working Paper 130.

Crouzel, Y. (2004), Refonder l'Etat par le local: gouvernement local et institutionnalisation d'un Etat post-apartheid en Afrique du Sud. Universidade Montesquieu-Bordeaux IV: IEP-CEAN.

Darbon, D. (2003), "Réformer ou reformer les administrations projetées des Afriques. Entre routine anti-politique et ingénierie politique contextuelle”, Revue Française d'Administration Publique, 105/106, 136-137.

Dubresson, A. et al. (1994), "Qui dirige la ville? Pouvoirs locaux et gestion urbaine en Afrique australe (Botswana, Malawi, Namibie, Zambie, Zimbabwe)", Chroniques $d u$ SUD, 13, 72-77.

Ferguson, J. (1990), The Anti-Politics Machine: Depoliticization and Bureaucratic Power in Lesotho. Cambridge: CUP.

Gore, C. (2000), "The Rise and Fall of the Washington Consensus as a Paradigm for Developing Countries", World Development, 28, 789-804.

Hermet, G. et al. (1978), Des élections pas comme les autres. Paris: Presses de la FNSP.

Hermet, G. et al. (org.) (2005), La gouvernance. Un concept et ses applications. Paris: CERI, Karthala.

Hibou, B. (1999), "La décharge, nouvel interventionnisme”, Politique Africaine, 73, 6-15.

Jobert, B. (2002), Le mythe de la gouvernance antipolitique. Colóquio da AFSP, Lille, 18 a 21 de Setembro de 2002 (policop.).

Le Bris, E. (1999), "La construction municipale en Afrique. La laborieuse gestation d'un espace public", Politique Africaine, 74, 6-12. 
Loada, A.; Otayek, René (1995), "Les élections municipales du 12 février 1995 au Burkina Faso", Politique Africaine, 58, 135-142.

Lonsdale, J. (1990), “Le passé de l'Afrique au secours de son avenir”, Politique Africaine, 39, 126-146.

Mamadou, M. Goita (2003), "Communalisation et gestion du territoire: une incursion dans le commune de Niangoloko au Burkina Faso", in M. Totté et al., La décentralisation en Afrique de l'Ouest. Entre politique et développement. Paris: Karthala-COTA-ENDA GRAF, 277-290.

Mamdani, M. (1996), Citizen and Subject: Contemporary Africa and the Legacy of Late Colonialism. Princeton NJ: Princeton University Press.

Médard, J.-F. (1990), “L’Etat patrimonialisé”, Politique Africaine, 39, 25-36.

Newbury, C. (1994), "Introduction: Paradoxes of Democratization in Africa”, African Studies Review, 37(1), 1-8.

Olowu, D.; Wunsch, J.S. (orgs.) (2004), Local Governance in Africa: The Challenges of Democratic Decentralization. Boulder: Lynne Rienner Publishers.

Otayek, René (org.) (2002), "La société civile: une vue du Sud”, Revue Internationale de Politique Comparée, 9(2).

Otayek, René (2004), "Civil Society and Democracy: A Critical and Comparative View from an African Perspective”, in Maria Cristina Ercolessi; Alessandro Triulzi (orgs.), State, Power and New Political Actors in Postcolonial Africa. Milano: Feltrinelli, 131-152.

Otayek, René (2000), Identité et démocratie dans un monde global. Paris: Presses de Sciences Po.

Pollard, R. (1993), “La démocratie ambiguë”, L’année africaine 1992-1993. Bordeaux: CEAN-CREPAO, 47-48.

Pontier, J.-M. (1978), L'Etat et les collectivités locales: la répartition des compétences. Paris: LGDJ.

Poutignat, P.; Streiff-Fenart, J.-S. (orgs.) (1995), Théories de l'ethnicité. Paris: PUF. Ribot, J. C. (2002), African Decentralization: Local Actors, Powers and Accountability. Geneve: UNRISD.

Stiglitz, Joseph E. (2002), Mondialisation - La grande désillusion. Paris: Fayard.

Utting, P.; Jaubert, R. (orgs.) (1998), Discours et réalité des politiques participatives de gestion de l'environnement. Le cas du Sénégal. Genève: IUED, UNRISD.

Vénard, J.-L. (1993), "Bailleurs de fonds et développement local”, in S. Jaglin; A. Dubresson (orgs.), Pouvoirs et cités d'Afrique noire. Décentralisations en questions. Paris: Karthala, 19-33. 